\title{
Determining the Operator for the Public Toll Road
}

\author{
Bin Shang $\mathbb{D}^{1},{ }^{1}$ Qiang Sun, ${ }^{2}$ Hao Feng $\mathbb{D}^{3,4}$ and Jiancong Chang ${ }^{1}$ \\ ${ }^{1}$ Shanghai Jian Qiao University, Shanghai 201306, China \\ ${ }^{2}$ China Northeast Municipal Engineering Design and Research Institute, Changchun 130021, China \\ ${ }^{3}$ The Key Laboratory of Road and Traffic Engineering, Ministry of Education, Tongji University, Shanghai 201804, China \\ ${ }^{4}$ Academy of Forensic Science, Shanghai 200063, China \\ Correspondence should be addressed to Hao Feng; fengh@ssfjd.cn
}

Received 13 October 2020; Revised 24 December 2020; Accepted 31 December 2020; Published 18 January 2021

Academic Editor: Chunjiao Dong

Copyright (c) 2021 Bin Shang et al. This is an open access article distributed under the Creative Commons Attribution License, which permits unrestricted use, distribution, and reproduction in any medium, provided the original work is properly cited.

\begin{abstract}
After the BOT road operation contract expires, generally, the road will be transferred to the government, and then the government operates the road independently without charging costs from its users. Facing the huge amount of the operation cost, Chinese government tends to continue to charge the road users to guarantee the high quality of road operation. Then, the government will have to decide whether a private firm or government itself would be suitable to operate the road. A model is presented for decisionmaking through balancing interests between the government and the private firm with an introduction of an intermediate variable, i.e., bidding price. Three scenarios are investigated in the model, including the optimization of government operation, the optimization of private firm operation, and government operation with an improper decision of the intermediate variable. Improper intermediate variable will result in a higher toll charged by the government than by a private firm. The method of avoiding an improper decision is investigated. The result shows that the intermediate variable should be determined to be the government operation cost, based on which the private operator could be chosen, if available. With consideration of the private operator's profit to be guaranteed by the government, the maximum subsidy should be equal to the minimum private operator's profit to be disclosed when the contract is signed.
\end{abstract}

\section{Introduction}

Due to the tight government budget, a lot of transportation facilities, especially highways, were built in the buildoperate-transfer (BOT) mode in the past forty years. At present, more and more BOT contracts for the operation of roads have expired or will be going to expire.

When the roads previously operated in the BOT mode are transferred to the government, it is usually assumed that they will become public roads, and the government will take over the responsibility of operating and maintaining these roads with its own budget. In fact, the operation cost (OC) including but not limited to the maintenance cost is much less than the initial construction cost of the roads. In general, no toll will be charged for the public roads. In fact, in order to guarantee the standard of the service relating to the road operations, the government needs to invest heavily to cover the OC. Due to the tight fiscal budget and for decreasing the government financial burden, continuing tolling after the transfer of the roads becomes a logical decision and, to some extent, a universal operation mode. In fact, Chinese government intends to charge the fees for these roads [1]. Chinese government could decide either to charge in its own name or entrust a private firm with this task.

Based on the above description, the road outside the BOT concession period is referred to as the public toll road (PTR) hereinafter, and the toll will be charged continuously to make up the OC. Tan et al. [2] and Niu and Zhang [3] pointed out that normally, a private firm would define the whole road life cycle as the BOT concession period in the BOT contract. However, it is not the case in China. All the BOT roads will have to be transferred to the government when the contracts expire. In this paper, we assume that PTR begins a new period after the road has been transferred to the government. The road life cycle, including the BOT concession period and PTR period, is illustrated in Figure 1. 


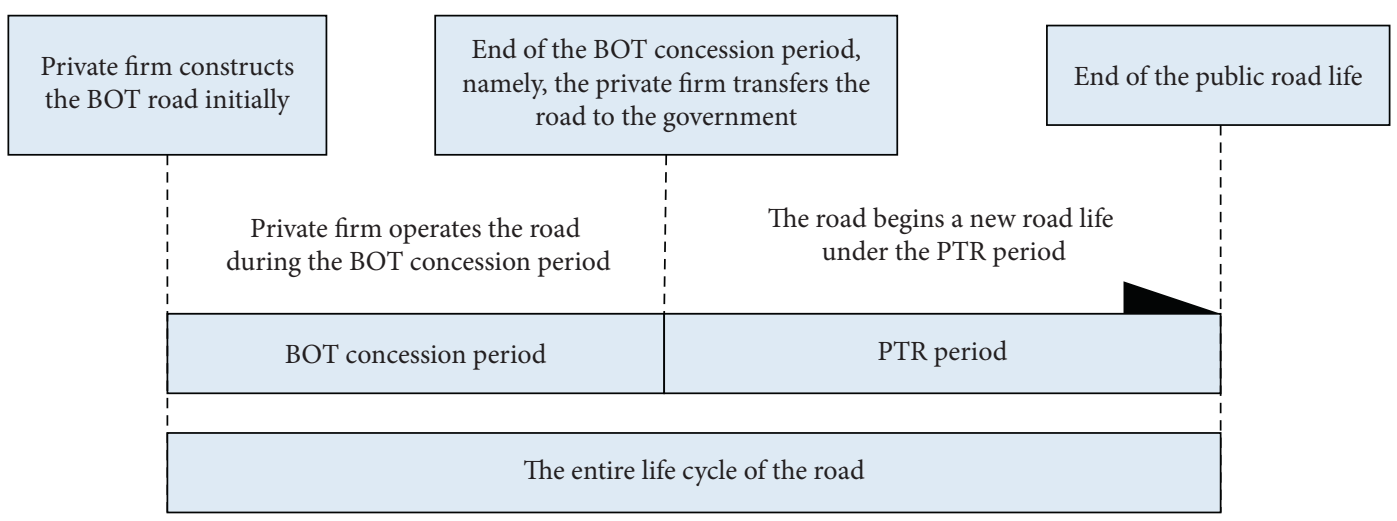

FIGURE 1: Relationship of the BOT concession period and PTC period.

There are numerous studies on the BOT road construction and operation [2-12]; however, few researchers consider the case after the roads are transferred to the government. To our best knowledge, the influence of OC during the PTR period has not been intensively studied yet. This paper aims to investigate whether the government or a private firm should operate the road under the charge of road toll if the government decides to charge to compensate the OC. This paper comes up with a new concept compared with previous studies concerning the BOT road. Previous research studies generally focus on the selection of the road operator among private firms in the BOT mode. This paper will explicitly examine the selection mechanism to determine whether the government or a private firm will operate the road under the charge of road toll during the PTR period. Note that the revenue collected from road users will be used to compensate the $\mathrm{OC}$, which is different from traditional pricing scenarios such as tolling for the return of the loan (BOT and public-private-partnership).

Referring to Shi et al.'s study [13], we regard that OC is composed of two parts: the demand-related OC and capacity-related OC. The demand-related OC denotes the cost relating to traffic demand; the capacity-related $\mathrm{OC}$ denotes the cost relating to the capacity of the road, including but not limited to the maintenance cost. Then, we introduced an intermediate variable presented by the government in the bidding document, which serves as perfect information to both government and private firms. The government and private firms are fully aware of their respective OCs, while the government is not clear about the potential profit to be earned by private firms. We consider the intermediate variable as crucial, based on which we studied the case by analyzing the relationship of the intermediate variable, OC of the private firm, and that of the government. The government may determine an improper intermediate variable based on the limited information. In contrast, we provide an optimal solution that the government sets its anticipated operation cost as the intermediate variable.

The remainder of the paper is organized as follows: Section 2 reviews the previous studies relating to toll road operation. Section 3 introduces the basic notations and assumptions necessary to our analysis model. Section 4 looks into the issue whether the government or a private firm is proper to operate the PTR under the condition that the toll is charged if the government decides to collect the toll to cover the OC. Section 5 investigates the optimal solution to be adopted by the government. Finally, Section 6 concludes this paper.

\section{Literature Review}

Literature on auction mechanisms of the BOT project is closely related to our research. These studies can let the government select the operator from several private firms efficiently. The least-present-value-of-revenue (LPRV) auction mechanism is used on highway franchise. According to auction theory [14], LPRV mechanism equaled to a type of auction: the first-price sealed-bid where the winner was the firm who offered the lowest bid for total revenue. Engel et al. [5] presented a framework to evaluate different awarding mechanisms for the franchise contract, and based on the LPRV auction mechanism, they presented a simple auction. Furthermore, Engel et al. [15] showed that the commonly used fixed-term contract of franchise highway did not allocate the demand risk optimally and then proposed a new auction mechanism for the franchise highway based on the LPRV mechanism.

On the variable-term-based concept [5], Rus and Nombela [16] pointed out that if operation cost was not negligible, the LPVR mechanism would not guarantee the best concessionaire; then, they proposed the least-presentvalue-of-net-revenue (LPRNV) mechanism which required private firm making offers on total revenue, maintenance costs, annual operation and routine maintenance cost, and so on; and this mechanism eliminated the demand risk effectively. Based on a flexible-term contract and bidimensional bids for maintenance costs and total net revenue, Nombela and de Rus [17] proposed a new franchising mechanism, comparing with fixed-term concessions, which could promote the selection of efficient concessionaires through eliminating the traffic risk. Verhoef [18] investigated welfare impacts of franchise regimes for congestible toll roads and found that patronage-maximizing auction was not optimal when considering the second-best network 
aspects. Ubbels and Verhoef [19] looked into how to get the desired welfare through analyzing the auction rules which were set by the government in the process of bidding and found that a bid with minimal price on the toll road would lead to satisfying results for unsubsidy auction; however, considering subsidies, the best bid would appear to involve the minimum generalized travel costs. van den Berg [20] investigated private supply of two congestible infrastructures under four market structures including a monopoly and three duopolies that differed in how private firms interact with each other and found that a duopoly could lead to a different rule of capacity than the first-best one which differed from the duopoly with the facilities.

However, all the above studies focus on the BOT road operation as well as how to choose a private road operator. Any existing selection mechanisms decide a private road operator without considering the government as one of the potential road operators. Therefore, compared to the previous studies, we investigate a mechanism to select the best party to operate the road during the PTR period among the government and private firms.

\section{Notation and Assumptions}

As mentioned above, we are aware that Chinese government will have to decide whether to collect the toll in its own name or to entrust a private firm with this task. Furthermore, we assume that the PTR is the unique one connecting two neighboring cities, and the private firms are able to operate the road in a more efficient and profitable way than the government. Besides, we further assume that the social welfare for the public and the private firm's profit derived from operating the PTR are functions of the toll pricing and the road capacity.

Let $v \geq 0$ and $c \geq c_{1}$ be the travel demand and road capacity, respectively, which are measured by the number of vehicles per unit time; $c_{1}$ is the road capacity when it is transferred to the government. Let $B(v)$ be the inverse demand function (or a function of the marginal benefit) and $t(v, c)$ be the travel time function. Moreover, the demand-supply equilibrium condition holds, i.e., $B(v)=p+\beta t(v, c)$, where $p$ is the toll charged by the operator and $\beta$ is the value of time that converts time into an equivalent monetary cost. The above condition means that the travel demand of a new road is determined by the total cost (including travel time and toll collected from road users) of a trip. In this paper, we only consider homogeneous users. Subsequently, we get a price function:

$$
p(v, c)=B(v)-\beta \cdot t(v, c) .
$$

Equation (1) implies that the toll $p$ is determined by travel demand $v$ uniquely for a given road capacity $c$. Hereinafter, $v$ and $c$ are equivalent to $p$ and $c$.

Let $M_{s}(v)$ and $M_{g}(v)$ be the demand-related OC of a private firm and the government, respectively. Let $M_{d}(v)$ be an intermediate demand-related OC which is a function of the intermediate variable. Then, we have

$$
\begin{aligned}
& M_{s}(v)=m_{s} v, \\
& M_{g}(v)=m_{g} v, \\
& M_{d}(v)=m_{d} v,
\end{aligned}
$$

where $m_{s}$ and $m_{q}$ are the unit demand-related OC of the private firm and the government, respectively, and $m_{d}$ is the intermediate variable.

Let $J_{s}(v, c)$ and $J_{g}(v, c)$ be the OC of a private firm and the government, respectively. Let $J_{d}(v, c)$ be an intermediate OC. Then, we have

$$
\begin{aligned}
& J_{s}(v, c)=I(c)+M_{s}(v)=I(c)+m_{s} v, \\
& J_{g}(v, c)=I(c)+M_{g}(v)=I(c)+m_{g} v, \\
& J_{d}(v, c)=I(c)+M_{d}(v)=I(c)+m_{d} v,
\end{aligned}
$$

where $I(c)$ is the capacity-related OC of the toll road. The construction material information of a road is known in the market, so we assume that $I(c)$ is the perfect information and identical for a private firm and the government in the paper. Given the same $I(c)$, we can regard $m_{d}$ as the intermediate variable that is set by the government in the bidding document. In practice, based on $m_{d}$, the government will evaluate the road OC including the management cost and construction cost before determining the road operator. Throughout this paper, we make the following assumptions on $B(v), t(v, c), M_{s}(v), M_{g}(v)$, and $I(c)$.

\section{Assumption 1}

(a) The inverse demand function, $B(v)$, is a strictly continuously decreasing and differentiable function of $v$ for any $v \geq 0$.

(b) The travel time function $t(v, c)$ is a continuously differentiable and strictly convex function of $v$ and $c$ for $v \geq 0$ and $c \geq 0 . t(v, c)$ strictly decreases with $c$ for $v>0$ and strictly increases with $v$ for $c \geq c_{1}$.

(c) The demand-related OC function of the government, a private firm, and the intermediate variable, $M_{g}(v), M_{s}(v)$, and $M_{d}(v)$, are continuously increasing and differentiable with respect to $v$ for $v \geq 0$; the road construction cost function $I(c)$ is continuously increasing and differentiable with respect to $c$ for $c \geq c_{1}$.

(d) For any given $c \geq c_{1}$, the revenue collected from road users is given by $R(v, c)=v \cdot p(v, c)$, which is a strictly concave function of $v$ for $v \geq 0$, i.e., $\partial R^{2} / \partial v^{2}<0$.

It is assumed that the government knows the OC of a private firm, but is not clear of its profit; so, the government will select a private firm through a determined intermediate variable $m_{d}$. With the given intermediate variable $m_{d}$, the problem in the following cases can be analyzed. If private firms take part in the bidding process and obtain the right to operate the PTR with $m_{d}$, the selection procedure will terminate. If the government sets the value of $m_{d}$ too high, there will be no private firms participating in the bidding. The government has to take the right approaches to avoid 
this situation. In order to offer proposals for the government to make a proper decision, two solution approaches are proposed: set the right value of the intermediate variable; provide guarantee for the private firms to ensure their profit. If not selecting a private firm to operate the PTR, the government will operate the road by itself.

We first consider the profit of both roles. Let $P_{g}(v, c)$, $P_{s}(v, c)$, and $P_{s c}(v, c)$ be the governmental profit, private firm profit without governmental guarantee, and private profit with governmental guarantee, respectively.

$$
\begin{aligned}
P_{g}(v, c)= & R(v, c)-J_{g}(v, c)=v \cdot B(v)-v \beta t(v, c) \\
& -\left[I(c)+m_{g} v\right], \\
P_{s}(v, c)= & R(v, c)-J_{s}(v, c)=v \cdot B(v)-v \beta t(v, c) \\
& -\left[I(c)+m_{s} v\right], \\
P_{s c}(v, c, n)= & R(v, c)-J_{s}(v, c)+n=P_{s}(v, c)+n,
\end{aligned}
$$

where $R(v, c)$ is the total revenue obtained from the road users; the last term of equation (5) is the government guarantee that the government will offer subsidy for the private firm operating the PTR. Equation (5) shows that private firm profit includes two parts: one is profit from the project $P_{s}(v, c)$, and the other is the government subsidy $n$. Then, the revenue is

$$
R(v, c)=v \cdot p(v, c)=v \cdot B(v)-v \beta t(v, c) .
$$

Next, we define the function of social welfare. When the government operates the road, the social welfare function is formulated as

$$
W_{g}(v, c)=U_{s}+P_{g}(v, c)=\int_{0}^{v} B(w) \mathrm{d} w-\beta v t(v, c)-J_{g}(v, c),
$$

where $U_{s}$ is the total social surplus.

With equation (1), the total social surplus is defined by

$$
U_{s}=\int_{0}^{v} B(w) \mathrm{d} w-v B(v)=\int_{0}^{v} B(w) \mathrm{d} w-v[p(v, c)+\beta t(v, c)] .
$$

When the private firm operates the toll road without the government guarantee, the social welfare is given by

$$
W_{s}(v, c)=U_{s}+P_{s}(v, c)=\int_{0}^{v} B(w) \mathrm{d} w-\beta v t(v, c)-J_{s}(v, c) .
$$

When the private firm operates the toll road with the government guarantee, the social welfare can be computed as

$$
\begin{aligned}
W_{s c}(v, c)= & U_{s}+\delta \cdot P_{s c}(v, c)-n=\int_{0}^{v} B(w) \mathrm{d} w \\
& -(1-\delta) v B(v)-\beta v t(v, c)-\delta J_{s}(v, c)-(1-\delta) n,
\end{aligned}
$$

where $\delta$ is a weighting factor, $0<\delta<1$. The first term on the right side of equations (7)-(10) is the total social surplus of road users; the second term of equation (7) is the government profit; the second term of equation (9) is the private profit; the second term of equation (10) is the weighted provider's surplus [21]; and the last term of equation (10) is the government guarantee.

\section{Assumption 2}

(a) $t(v, c)$ is homogeneous of degree zero in $v$ and $c$, i.e., $t(\alpha v, \alpha c)=t(v, c)$ for any $\alpha>0$

(b) Constant return to scale in the construction and capacity-related cost, namely, $I(c)=k c$, where $k$ denotes the constant cost per unit capacity

(c) $v B(v)$ is a concave function of $v$ for any $v \geq 0$

Part (a) of Assumption 2 shows that vehicle travel time on the road is only related with the volume-capacity ratio, $r=v / c$. For example, the BPR (Bureau of Public Roads) travel time function satisfies this assumption. In equation (1), the toll $p$ can be uniquely determined by the travel demand $v$ for a given road capacity $c$. In other words, social welfare and profit, created by both the government and a private firm, are determined by the travel demand $v$, road capacity $c$, and the government subsidy $n$.

\section{The First Selection of the PTR Operator by the Government}

The government has the right to set an intermediate variable $m_{d}$ as the threshold value of the public toll road for private firms. The government will not select $m_{d}>m_{g}$; otherwise, it will operate the road by itself. So, when the government aims to choose a private firm to build/rebuild and operate the road, obviously, it will set the intermediate variable $m_{d} \leq m_{g}$.

4.1. Under the Condition of $m_{s}>m_{g}$ with the Government Operation. The government and private firm know the information of OC for each other. When the unit demandrelated $\mathrm{OC}$ of the private firm is greater than the government's, namely, $m_{s}>m_{g}$, the government will operate the PTR by itself to maximize social welfare. In order to distinguish from the analysis of Section 4.3, the superscript " $s>g$ " is used to represent the case $m_{s}>m_{g}$. Then, if $m_{s}>m_{g}$, the unconstraint social welfare maximization problem is formulated as

$$
\max _{(v, c)} W_{g}^{s>g}(v, c)=\int_{0}^{v} B(w) \mathrm{d} w-\beta v t(v, c)-J_{g}^{s>g}(v, c),
$$

where the first-order optimal conditions of equation (11) can be found in Tan et al. [2].

There are many highways operated by the government in China. The government needs the revenue collected from the road users at least to cover the road investment including operation and construction cost. So, when analyzing the operating PTR, it is necessary to analyze the social welfare maximization under the condition that the total investment including but not limited to operation costs is equal to the total revenue $R(v, c)$, namely, the road operator obtains 
positive profit or zero profit from the project. Then, if the government operates the road on its own, the constrained problem is defined as

$$
\max _{(v, c)} W_{g}^{s>g}(v, c)=\int_{0}^{v} B(w) \mathrm{d} w-\beta v t(v, c)-J_{g}^{s>g}(v, c),
$$

subject to

$$
\begin{aligned}
P_{g}^{s>g}(v, c) & =R_{g}^{s>g}(v, c)-J_{g}^{s>g}(v, c) \geq 0, \\
v & \geq 0, \\
c & \geq c_{1},
\end{aligned}
$$

where equation (13) implies nonnegative profit; $P_{g}^{s>g}(v, c)$ is the profit of the government; and $R_{g}^{s>g}(v, c)$ is the governmental revenue.

4.2. Under the Condition of $m_{s} \leq m_{g}$ with the Private Firm Operation. In practice, the OC of a private firm, with stronger execution and more flexibility, is usually lower than that of the government. If the government makes a correct decision on $m_{d}$, the private firm will be willing to operate the PTR with proper profit. In this section, we first propose the condition that the private firm operates the road under the condition of $m_{s} \leq m_{g}$; then, based on the unconstrained and constrained maximization private profit models, the definitions of the first-best and second-best problems for the private firm are provided, respectively. For simplicity, the subscript " $s$ " was used to denote $m_{s} \leq m_{g}$.

First, the following proposition provides the condition for the private firm to operate the road. We assume the acceptable profit to be $P_{a}$.

Proposition 1. If the sum of the unit demand-related OC and unit benefit of the private firm is less than $m_{d}$, namely, $m_{s}+P_{a} / v \leq m_{d}$, and the government sets $m_{d}$ in the interval $\left[m_{s}+P_{a} / v, m_{g}\right)$, then the contract between the government and a private firm will be signed.

Proof. If allowed to operate the PTR, the private firm will aim to make maximal profit from the project; and the government will certainly not let the private firm get so much profit. In other words, the private profit will be less than the difference between the intermediate OC and the OC of the private firm. Then, we have

$$
\begin{aligned}
& v \cdot p(v, c)-J_{s}(v, c) \geq P_{a}, \\
& v \cdot p(v, c)-J_{s}(v, c) \leq J_{d}(v, c)-J_{s}(v, c)
\end{aligned}
$$

such that

$$
J_{d}(v, c) \geq P_{a}+J_{s}(v, c)
$$

Since $I(c)$ is the perfect information,

$$
M_{d}(v) \geq P_{a}+M_{s}(v) .
$$

The proof is completed.
Although Proposition 1 includes the OC of the private firm and the intermediate OC, it does not mean that the government knows the amount of the private profit. In reality, only when the government sets the intermediate variable $m_{d}$, the private firm will decide whether or not to operate the road according to its $\mathrm{OC}$ and profit. However, the government usually evaluates the trade secret $P_{a}$ of private firms to determine $m_{d}$.

Getting the road franchising, the private firm will maximize its profit by selecting the road capacity $c$ and toll $p(c)$. In the extreme case of the private profit maximization without any constraints, the unconstraint optimal problem can be formulated as

$$
\max _{(v, c)} P_{s}(v, c)=v p(v, c)-J_{s}(v, c) .
$$

Then, we investigate the profit maximization under the constraint that the private profit is not larger than the difference between the intermediate OC and the private firm OC. The constrained optimization problem can be formulated as

$$
\max _{(v, c)} P_{s}(v, c)=v p(v, c)-J_{s}(c)
$$

subject to

$$
\begin{gathered}
v p(v, c)-J_{s}(v, c) \geq P_{a} \\
v p(v, c)-J_{s}(v, c) \leq J_{d}(v, c)-J_{s}(v, c) \\
m_{s}<m_{d} \leq m_{g} \\
v \geq 0 \\
c \geq c_{1} \\
P_{a} \geq 0
\end{gathered}
$$

where $P_{a} \geq 0$ is the minimum profit of the private firm. Even if $m_{d}>m_{s}$, the government is still willing to let a private firm operate the road, which meets constraint (20). Alternatively, only when the private profit is larger than the profit margin $P_{a}$, the private firm will be willing to operate the road. Constraint (21) means that the private firm profit will not be larger than the difference between the intermediate OC and the private firm OC, and the government will permit the private firm to operate the PTR.

Based on the aforementioned problems, the definition of the first-best and second-best solutions of the private firm is introduced.

Definition 1. (first-best and second-best profit solutions of the private firm). Let $\left(v_{s}, c_{s}\right)$ be an optimal solution to optimal problems (19)-(22); it will be the first-best solution if it maximizes problem (18); otherwise, it will be the secondbest solution.

Definition 1 is based on the profit maximization that could classify the private profit problems. It is different from the definition of the first-best and second-best contracts based on the social welfare [22]. In fact, the private firm will easily reach the second-best solution with constraints (20) 
and (21). By comparing first-best problem (18) and secondbest problems (19)-(22), the following observation can be obtained based on Definition 1.

Observation 1. The first-best solution of the private firm exists if there only exists a solution $\left(v_{s}^{*}, c_{s}^{*}\right)$, which solves the first-best problem and satisfies

$$
\begin{gathered}
v \cdot p\left(v_{s}^{*}, c_{s}^{*}\right)-J_{s}\left(v_{s}^{*}, c_{s}^{*}\right) \geq P_{a}, \\
v_{s}^{*} \cdot p\left(v_{s}^{*}, c\right)-J_{d}\left(v_{s}^{*}, c_{s}^{*}\right) \leq 0 .
\end{gathered}
$$

The above observation is intuitive. If the total revenue generated by the first-best profit solution can cover the OC and create an acceptable profit threshold for the private firm, then the first-best profit solution can be archived.

From Definition 1 and Observation 1, it is clear that if the government permits the private firm to determine the optimal profit by itself, the private firm will choose either the first-best or second-best solution, but not both. The first-best solution exists only if conditions (23) and (24) are satisfied; otherwise, the private firm will obtain the second-best solution. Therefore, to solve private profit problems (19)-(22), it is necessary to solve problem (18) and check whether its solution satisfies constraints (23) and (24). If these conditions hold, it is unnecessary to consider problems (19)-(22).

The Kuhn-Tucker conditions can be applied to obtain the first-order conditions (Appendix A). Note that let $P_{s}^{s b}$ be the optimal value of the objective function of problems (19)-(22), and it distinguishes from the value of $\bar{P}_{s}$ that is a monopoly optimal solution of problem (18). The relationship between $P_{s}^{\text {sb }}$ and $\bar{P}_{s}$ is that $P_{s}^{\text {sb }} \leq \bar{P}_{s}$, and $P_{s}^{\text {sb }}$ is on the left side of $\bar{P}_{s}$ in Figure 2. The following observation about $P_{s}^{s b}$ can be obtained through analyzing the constraints.

\section{Observation 2}

(a) If constraints (20) and (21) are effective, the acceptable private firm profit is equal to the maximal profit $J_{d}-J_{s}$, namely, $P_{s}^{\text {sb }}=P_{a}=J_{d}-J_{s}=M_{d}-M_{s}$

(b) If constraint (20) is effective but constraint (21) is inactive, the private firm profit is $P_{s}^{s b}=P_{a}$

(c) If constraint (21) is effective but constraint (20) is inactive, the private firm profit is $P_{s}^{\mathrm{sb}}=J_{d}(v, c)-J_{s}(v, c)$

(d) If both constraints (20) and (21) are ineffective and the second-best problem becomes the first-best problem, then the private firm profit is $P_{s}^{\mathrm{sb}}=\bar{P}_{s}$

From the aforementioned observations, we investigate the case of the first-best and second-best private profit problem, which is presented on the left side of the monopoly optimum in Figure 2. However, when will the monopoly optimum case happen? As shown in Figure 2, we can see that, responding to the same private profit, social welfare on the right side of the monopoly optimum is higher than that on the left side. Additionally, the government can make some rules in the contract to make the private firm set the social welfare maximization as the goal [23]. So, it is necessary to analyze the following two problems with private firm management: one is the unconstrained social welfare maximization problem; the other is the constrained social welfare maximization problem.

Base on equation (7), the unconstrained social welfare maximization problem can be formulated by

$$
\max _{(v, c) \in \Omega} W_{s}(v, c)=\int_{0}^{v} B(w) \mathrm{d} w-\beta v t(v, c)-J_{s}(v, c) .
$$

The constrained social problem is given by

$\max _{(v, c) \in \Omega} W_{s}(v, c)=\int_{0}^{v} B(w) \mathrm{d} w-\beta v t(v, c)-J_{s}(v, c)$,

subject to

$$
\begin{aligned}
v p(v, c)-J_{s}(v, c) \geq P_{a} \\
v p(v, c)-J_{s}(v, c) \leq J_{d}(v, c)-J_{s}(v, c) \\
m_{s}<m_{d} \leq m_{g} \\
v \geq 0 \\
c \geq c_{1} \\
P_{a} \geq 0
\end{aligned}
$$

where $\Omega=\{(v, c): v \geq 0, c \geq 0\}$. The constrained conditions are the same as those of the second-best problem of the private firm, i.e., (20)-(22), which guarantee the private firm to operate the road.

Since this kind of constrained social welfare problem has more constraints than the traditional Pareto optimal problem, the win-win optimal problem is defined as follows.

Definition 2. (win-win optimal problem). A pair $\left(v_{s}^{\mathrm{ww}}, c_{s}^{\mathrm{ww}}\right) \in \Omega$ is called the win-win solution if there are no other feasible solutions $(v, c) \in \Omega$ such that $W(v, c) \geq W\left(v_{s}^{\mathrm{wW}}, c_{s}^{\mathrm{ww}}\right)$ and $P(v, c) \geq P\left(v_{s}^{\mathrm{wW}}, c_{s}^{\mathrm{ww}}\right)$ with at least one strict inequality.

The definition of the win-win optimal problem is a meaningful and important concept which meets all the conditions of the Pareto problem, but with more constraints, and its solution is a part of the Pareto optimal solution.

In general, more than one constrained condition in problems (27)-(29) will be effective. In response to the case on the right side of monopoly optimum in Figure 2, similar to Observation 2 , the following observation is provided through analyzing the constrained conditions (Appendix B).

\section{Observation 3}

(a) If constraints (27) and (28) are effective, the acceptable private firm profit is the same as its maximal profit, which is equal to $J_{d}-J_{s}$, namely, $P_{a}=M_{d}-M_{s}$

(b) If constraint (27) is effective and constraint (28) is inactive, the private firm profit is equal to $P_{a}$ 


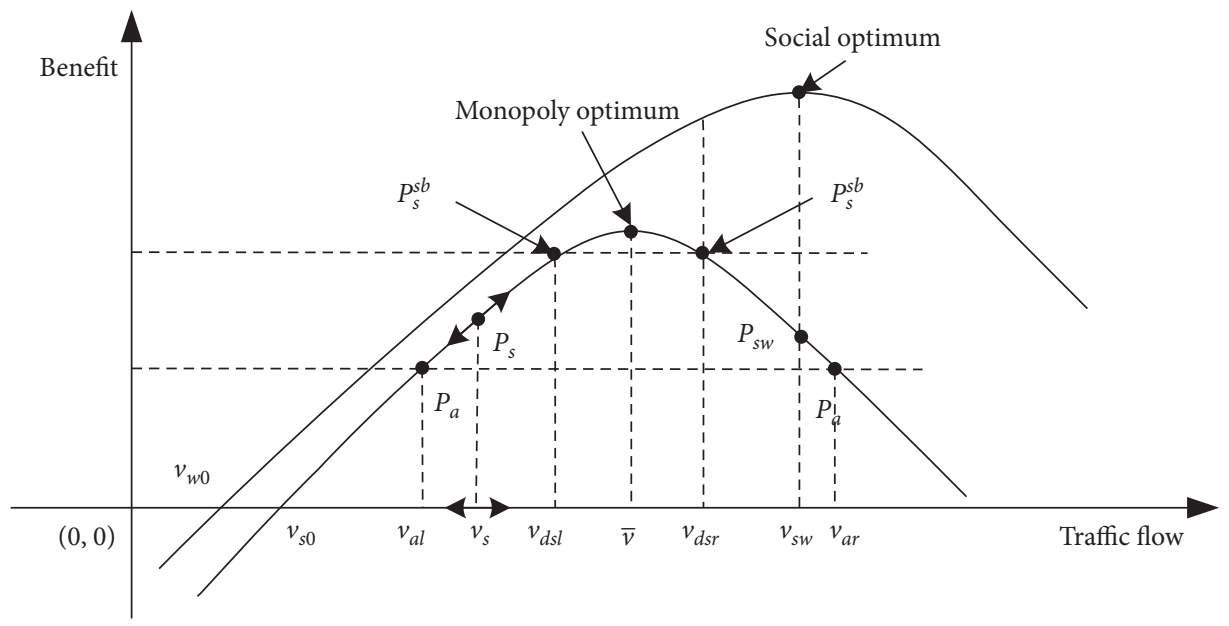

Figure 2: A geometric illustration of $P_{a}, \bar{P}_{s}, P_{s}$, and $P_{s}^{\mathrm{sb}}$.

(c) If constraint (28) is effective and constraint (27) is inactive, the private firm profit is equal to $M_{d}-M_{s}$

Furthermore, let $\widetilde{v}_{s}$ and $\bar{v}_{s}$ be the social welfare optimality solution of problem (18) and the monopoly optimal solution of problem (25), respectively. The following proposition is obtained in terms of the above second-best solution of the private problem and win-win optimal problem (see more details in Appendix C).

Proposition 2. It holds that $v_{s}^{\mathrm{sb}}<\bar{v}_{s} \leq v_{s}^{\mathrm{ww}} \leq \widetilde{v}_{s}$ for the winwin optimal solution $\left(v_{s}^{\mathrm{ww}}, c_{s}^{\mathrm{ww}}\right)$ and the second-best solution of the private firm $\left(v_{s}^{\mathrm{sb}}, c_{s}^{\mathrm{sb}}\right)$ when the private firm operates the road.

Proposition 2 means that travel demand of the win-win solution should not be strictly less than the level of the profit maximization and less than the level of the social welfare maximization. Travel demand of the second-best optimal solution is smaller than that of any other optimal solutions. Figure 2 implies that the government must set the regulation to gain the win-win optimal solution, namely, make $M_{d}-$ $M_{s}$ on the right side of the monopoly optimal solution. Otherwise, the private firm will optimize the travel demand $v_{s}^{\mathrm{sb}}$.

Based on the second-best solution and the Win-Win optimal solution, Proposition 3 can be derived:

Proposition 3. For the second-best solution of the private firm, the bigger $M_{d}-M_{s}$ is, the more possible it is that the government and a private firm have the same objective; For the win-win solution, the smaller $M_{d}-M_{s}$ is, the more possible it is that the government and private firm have the same objective.

Refer to the proof in Appendix D. Proposition 3 tells us why the private firm wants to know the value of $M_{d}$ and the government also wants to evaluate the demand-related OC of the private firm to set a better $M_{d}$. The result is consistent with Figure 2, which implies the objective of the government and private firm will be realized at the same time on the left side of monopoly optimality, namely, the private firm obtains the maximum solution, while the government achieves the maximal social welfare. If the difference $M_{d}-M_{s}$ is bigger, the private firm will obtain more profit. On the right side of monopoly optimality in Figure 2, the government and private firm will have different objectives, namely, when the private firm chooses the profit maximization, the government will reach the minimum social welfare. If the difference $M_{d}-M_{s}$ is smaller, the private firm will obtain more profit, and the government can also gain more social welfare. However, welfare on the right side that belongs to the winwin optimal solution is bigger than that on the left side.

Let $P_{s w}$ be the private profit corresponding to the social optimal welfare. Based on Proposition 3, an extreme case is analyzed: if private profit satisfies $P_{a} \leq P_{s w}$, when the intermediate variable set by the government meets $\left(M_{d}-M_{s}\right) \geq P_{s w}$, namely, the variable relationship meets $P_{a} \leq P_{s w} \leq\left(M_{d}-M_{s}\right)$; under the win-win optimal regulation in the contract, not only that the government may gain the optimal social welfare but also the private firm meets its profit. So, the ideal condition is $P_{a} \leq P_{s w}=\left(M_{d}-M_{s}\right)$, which is also the best case for the win-win optimal solution.

Some private firms usually earn huge profit from the project, which happened in China such as Beijing Airport Expressway and Guangzhou-Shenzhen Highway. Although these roads were built with the largest road capacity (allowed by the design code), there is oversaturated traffic flow every day. In contrast with the traditional contract, we can regard constraint (21) as a regulation to allow the private firm to make the decision. Then,

$$
v p(v, c)-J_{s}(v, c)>J_{d}(v, c)-J_{s}(v, c) .
$$

The above condition implies that if the private firm profit is bigger than the difference between the intermediate $\mathrm{OC}$ and private firm OC, the government will operate the road by itself. Condition (30) can be simplified by

$$
v p(v, c)-\left[I(c)+m_{d} v\right]>0 .
$$

If there is heavy traffic pressure, then the private firm will get profit from the project quickly. Meanwhile, condition (31) implies that if the road is operated, all terms of (31) are the symmetric information for the government and a private 
firm, namely, the road capacity has been determined when the road is operating; the government can get the information of road capacity, toll, and travel demand from real data. Then, the government knows the profit of the private firm based on the intermediate variable even if it knows nothing about the private firm operation. When condition (31) is satisfied, the government can operate the road by itself, namely, condition (31) points out that the difference between profit $v p(v, c)$ and intermediate variable $m_{d}$ determines the road operation right of the private firm.

In the last part of this section, the private firm zero profit will be analyzed. If private firms get the road franchise, they will have the right to determine locations of on-ramps and offramps that have an impact on the land development, and so on. With the above description, the private firm will be willing to operate the toll road projects with zero profit or negative profit to earn more profit from other aspects. So, it is necessary to analyze the zero or negative profit case. However, in the light of knowing nothing about how much loss the private firm can bear, the zero profit is analyzed as follows.

Proposition 4. Under the condition of zero profit, the unit demand-related OC of the private firm $m_{s}$ can approach the biggest value, namely, $m_{s}$ is equal to $m_{g}$.

Proof. From constraints (20) and (21),

$$
J_{d}(v, c)-J_{s}(v, c) \geq P_{a} .
$$

If the private profit is equal to zero, namely, $P_{a}=0$, then

$$
M_{d}(v, c)-M_{s}(v, c)=0 .
$$

$$
\begin{aligned}
& \text { If } M_{d}(v, c)=M_{g}(v, c) \text {, then } \\
& M_{s}(v, c)=M_{g}(v, c) .
\end{aligned}
$$

The proof is completed.

4.3. Under the Condition of $m_{s} \leq m_{g}$ with the Government Operation. Different from Section 4.1, it is assumed that the government knows nothing about the private profit, which may make the government set an improper decision on the intermediate variable $m_{d}$. The private firm will not operate the road if it cannot gain the satisfied profit from the project. The following two cases are related with an improper decision of $m_{d}$.

In contrast with Section 4.2, we provide the condition that the private firm cannot gain enough profit. Using constraints (20) through (22),

$$
J_{d}(v, c)-J_{s}(v, c) \geq P_{a}
$$

which implies that only when the difference between the intermediate $\mathrm{OC}$ and the private $\mathrm{OC}$ is larger than the private firm profit, the private firm will be willing to operate the toll road.

On the contrary,

$$
J_{d}(v, c)-J_{s}(v, c)<P_{a},
$$

which implies that the government will be reluctant to operate the road by itself.
If $m_{d}$ given by the government is less than the private OC, namely, $m_{d} \leq m_{s}<m_{g}$, the private firm will not operate the road due to the negative profit.

In Section 4.1, we analyze the case that the government is willing to operate the road. In this section, there will be no contract between the government and a private firm. The superscript " $s<g$ " is used to represent $m_{s} \leq m_{g}$. Then, the problem can be formulated as

$$
\max _{(v, c)} W_{g}^{s<g}(v, c)=\int_{0}^{v} B(w) \mathrm{d} w-\beta v t(v, c)-J_{g}^{s<g}(v, c) .
$$

In the above analysis, two kinds of government operation scenarios were considered: the first one was analyzed in Section 4.1 given $m_{s}>m_{g}$; the second one was analyzed in this section under the condition of $m_{s} \leq m_{g}$. If the government does not make an improper decision on $m_{d}$, we assume that the government will choose to maximize the social welfare without loss, so it is not necessary to analyze this case. Edelson [24] showed that a private firm may charge a lower toll than the government for a given and fixed capacity. Let $c_{d}^{*}$ be the given road capacity, and all analyses of this section are based on this capacity. Then, we compare the toll charged by the government and the private firm based on the assumption that the government makes an improper decision on the variable $m_{d}$ under the condition of $m_{s} \leq m_{g}$. Note that the toll charged by the government is the solution at the zero profit, namely, the governmental revenue just covers its capital cost.

Then, we define the average social cost (ASC) of the government and private firm, respectively:

$$
\operatorname{ASC}_{g}^{s<g}=\frac{\beta v t\left(v, c_{d}^{*}\right)+J_{g}^{s<g}\left(v, c_{d}^{*}\right)}{v}=\beta t\left(v, c_{d}^{*}\right)+\frac{J_{g}^{s<g}\left(v, c_{d}^{*}\right)}{v},
$$

$$
\operatorname{ASC}_{s}=\frac{\beta v t\left(v, c_{d}^{*}\right)+J_{s}\left(v, c_{d}^{*}\right)}{v}=\beta t\left(v, c_{d}^{*}\right)+\frac{J_{s}\left(v, c_{d}^{*}\right)}{v} .
$$

The first term of equations (38) and (39) on the right side is the average travel time in monetary units; the second term is the cost of operation per trip. Intuitively, with Assumptions 1 and 2 and the condition of $m_{s} \leq m_{g}$, the average social cost of the government will be bigger than the private firm OC for given road capacity and travel demand.

If considering the average social profit in the cost of the private firm, equation (39) can be rewritten as

$$
\operatorname{ASC}_{s p}=\beta t\left(v, c_{d}^{*}\right)+\frac{J_{s}\left(v, c_{d}^{*}\right)}{v}+\frac{P_{s}}{v} .
$$

Then, combining equations (38) and (40) for the given travel demand and road capacity $c_{s}^{*}$,

$$
\mathrm{ASC}_{g}^{s<g}-\mathrm{ASC}_{s p}=\frac{M_{g}^{s<g}(v)-\left[M_{s}(v)+P_{s}\right]}{v}
$$

where $P_{s}$ is in the interval $\left[P_{a}, M_{d}-M_{s}\right]$.

From equation (41), though $P_{s}=M_{d}-M_{s}$, the average social cost of the government will be bigger than that of 
private firm operation under $M_{d} \leq M_{g}$. We know that the government may charge a higher toll than the private firm under the condition that the government operates the road without loss.

Let $\bar{p}_{s}, \widetilde{p}_{s}$, and $\widetilde{p}_{g}^{s<g}$ be the monopoly price of the private firm, the price of social optimal welfare of the private firm, and the price of social optimal welfare of the government, respectively. Then, the following proposition can be obtained (Appendix E).

Proposition 5. With a given road capacity $c_{d}^{*}$, the toll $\bar{v}_{s}, \widetilde{v}_{s}, \widetilde{v}_{g}^{s<g}$ has the following relationship: $\widetilde{p}_{s} \leq \widetilde{p}_{g}^{s<g}<\bar{p}_{s}$.

Proposition 5 shows that if the social welfare maximum is reached, the toll charged by a private firm is less than the government, which is derived from the improper decision of the government on the intermediate variable. In order to avoid the circumstance that the government operates the road with higher charge than the private firm, the best option for the government is investigated to get a satisfactory result.

\section{The Optimal Intermediate Variable}

The case discussed in Section 4.3 occurs because of the improper intermediate variable $m_{d}$ given by the government. With the governmental operation, road users will pay higher toll that is analyzed in Section 4.3 for $m_{s} \leq m_{g}$. So, in order to find a proper private firm to operate the road and not let the road users undertake higher toll, the government will make a change on the selection tactics. In the following, two modes will be studied to avoid the improper decision on $m_{d}$ : one is without guarantee, and the other is considering guarantee provided by the government.

5.1. The Selection Mode without the Government Guarantee. At first, we investigate the mode that the government will not provide guarantee for the private firm. In Section 4, we discussed the case that the private firm and the government were willing to operate the road; we also discussed the case that the government was reluctant to operate the road under the improper decision. Under the condition of knowing nothing about private profit $P_{a}$, the government will try its best to make a correct decision. In Section 4, we pointed out that the case of $m_{d}>m_{g}$ was impossible in that the government would operate the road by itself. So, in this section, we only investigate the value of $m_{d}$ which can result in a satisfactory result for the government under $m_{d} \leq m_{g}$. We firstly provide the satisfactory result and unsatisfactory result under $m_{d} \leq m_{g}$ and $P_{a} \geq 0$.

The definition of satisfactory results:

(a)If $m_{d}=m_{g}$ and $m_{s}>m_{d}$, the government will operate the road by itself

(b) If $m_{s} \leq m_{d}=m_{g}$ and $m_{s}+P_{a} / v>m_{d}$, the government will operate the road by itself

(c) If $m_{s} \leq m_{d} \leq m_{g}$ and $m_{s}+P_{a} / v>m_{d}$, a private firm will operate the road

(d) If $m_{d}<m_{s} \leq m_{g}$ and $m_{s}+P_{a} / v>m_{d}$, the government will operate the road by itself
The definition of unsatisfactory results:

(e) If $m_{s} \leq m_{d}<m_{g}$ and $m_{s}+P_{a} / v>m_{g}$, the government will be reluctant to operate the road by itself

(f) If $m_{d}<m_{s} \leq m_{g}$ and $m_{s}+P_{a} / v>m_{g}$, the government will be reluctant to operate the road by itself

With the definition of satisfactory results and unsatisfactory results of the government, we have the following proposition. We know that there are two constraints: $m_{s}+$ $P_{s} / v>m_{d}$ and $P_{s} \geq P_{a}$. Then, we make another assumption that the government must obtain the satisfactory result.

Proposition 6. If the government wants to obtain a satisfied result, the intermediate variable $m_{d}$ should be equal to the demand-related OC of the government $m_{g}$, namely, $m_{d}=m_{g}$.

At the beginning of this section, we pointed out that the government is not clear about profit of the private firm. The governmental objective is to obtain the satisfied result with the private firm. If the government determines the value of the intermediate variable so that the private firms, after their independent calculation, believe that they will be able to make necessary profit from running the project, the private firms may decide to take part in the bid. The government does not need to know the OC of the private firm. So, when the government sets $m_{d}=m_{g}$, the government can easily choose a proper road operator under the condition of satisfactory results.

When $m_{d}=m_{g}$, the problem can be transformed to the following:

$$
\max _{(v, c)} W_{s}(v, c)=\int_{0}^{v} B(w) \mathrm{d} w-\beta v t(v, c)-J_{s}(v, c),
$$

subject to

$$
\begin{aligned}
v \cdot p(v, c)-J_{s}(v, c) & \geq P_{a}, \\
v \cdot p(v, c)-J_{s}(v, c) & \leq J_{g}(v, c)-J_{s}(v, c), \\
m_{s} & \leq m_{g}, \\
v & \geq 0, \\
c & \geq c_{1}, \\
P_{a} & \geq 0 .
\end{aligned}
$$

Then, the government can make the decision to obtain satisfactory results through comparing formulas (39)-(42) with the social optimal welfare problem in Section 4.3. Private firm can obtain its profit through setting the toll and road capacity based on the solution of problems (39)-(42).

5.2. The Selection Mode with the Government Guarantee. In this section, the government guarantee will be considered to make the government reach a satisfactory result. In order to obtain satisfactory results, like in Section 4.3, the government can make proper decisions through providing subsidy for the private firm.

We firstly give the condition that the government may provide the guarantee for a private firm: 


$$
v \cdot p(v, c)-J_{s}(v, c)=P_{s}(v, c)<P_{a} .
$$

From equation (44), we know that the private firm will not operate the road in that it will not get satisfactory profit from the project or get negative profit. If the government wants the private firm to operate the road, it must provide guarantee, namely, additional profit for the private firm, which makes sure the private profit is not less than a threshold value $P_{a}$ [25]. Then, we have

$$
P_{s c}(v, c)=P_{s}(v, c)+n=v \cdot p(v, c)-J_{s}(v, c)+n \geq P_{a},
$$

where the first term on the left side of the inequality is the private profit and $n$ is the government subsidy. Therefore, private profit is composed of a private firm profit and the government subsidy.

Even if providing subsidy for the private firm, the government will be reluctant that the total amount of profits, the $\mathrm{OC}$ of the private firm, and subsidies are bigger than the governmental OC. According to Proposition 6, we point out that $m_{d}=m_{g}$ is a better option for the government. Then, the second constraint becomes

$$
v \cdot p(v, c)-J_{s}(v, c)+n \leq J_{g}(v, c)-J_{s}(v, c) .
$$

Equation (46) can be simply written as $v \cdot p(v, c)+n \leq J_{g}(v, c)$. According to equation (46), the government can control the biggest subsidy which is $n=J_{g}(v, c)-v \cdot p(v, c)$. With this constraint, even if nothing is known about private profit, the government can determine the minimal subsidy. An extreme case is that the minimal private profit is equal to the maximum of guarantee, namely, $P_{a}=J_{g}(c)-J_{s}(c)$. From Proposition 6, as long as the subsidies do not exceed the maximum subsidies, the government will regard it as a satisfactory result.

In the bidding process, many private companies have put forward different subsidy requirements, which can further determine subsidies. If the government provides subsidies for the private firm, it must require a private firm to select the win-win optimal solution. With constraints (45) and (46) and objective function (10), the optimal problem with the government guarantee can be formulated by

$$
\begin{aligned}
\max _{(v, c)} W_{s c}(v, c, n)= & \int_{0}^{v} B(w) \mathrm{d} w-v B(v) \\
& +\delta\left[v \cdot p(v, c)-J_{s}(c)\right]-(1-\delta) n,
\end{aligned}
$$

subject to equations (45) and (46), and

$$
\begin{aligned}
m_{s} & \leq m_{g}, \\
v & \geq 0, \\
c & >c_{1}, \\
0 & <\delta<1, \\
P_{a} & \geq 0 .
\end{aligned}
$$

Based on the above problem, we have the following proposition (Appendix F).

Proposition 7. If the government provides guarantee for the private firm, the minimum private profit is equal to the maximum subsidies.

The above proposition shows that if the government wants to provide guarantee for the private firm, the private firm will choose the maximum subsides. And the government will not permit the total amount of toll sum charged by the private firm and guarantee larger than the governmental OC on the PTR.

\section{Conclusions}

The operation of the PTR becomes a significant issue of the government. This study offers valuable insights into the selection mechanism of PTR operators by comparing the $\mathrm{OC}$ of the government and the private firms. Previous studies conducted few research on the PTR operation. Considering a combination of the toll charge, road capacity, and guarantee, this paper analyses the operation problem through an intermediate variable. If the government sets the right intermediate variable in the bidding document, private firms will be willing to operate the road actively with the profit maximization. The first-best and second-best optimal solutions for the private firm and the win-win solution of the private operation were investigated. The average social cost and the toll charged by operators were compared; in some cases, the toll charged by the government is higher than private firms. The case that toll collected by the private firm from the road users is lower than that of the government will happen. Analytical results show that the social optimal pricing set by the private firm is less than that of the government, and then two approaches are proposed to solve the problem given a biased decision of the intermediate variable. The first approach sets the intermediate variable equal to the governmental OC without guarantee; the second one is that the government provides profit guarantee for the private firm.

To optimize the succeeding operation of different kinds of facilities developed in the BOT mode after the concession period expires, future research can be carried out under information asymmetry to investigate whether and how to charge the toll and to set regulations to be followed by the private firms when operating these facilities. Even if the government is in a position to build/rebuild and operate its transportation facilities, it is still necessary for it to seriously consider how to operate them in a sustainable way to maximize social welfare.

\section{Appendix}

\section{A. Proof of Observation 2}

Proof. It is assumed that $\left(v_{s}^{\mathrm{sb}}, c_{s}^{\mathrm{sb}}\right)$ is any second-best optimal solution of private problem (19). From constrained 
optimization problems (19)-(22), the following Lagrangelike function can be defined:

$$
L=P_{s}(v, c)+\lambda_{s b 1}^{s<g}\left[P_{s}(v, c)-P_{a}\right]+\lambda_{s b 2}^{s<g}\left[-v \cdot p(v, c)+J_{d}(v)\right],
$$

where $\lambda_{s b 1}^{s<g} \geq 0$ and $\lambda_{s b 2}^{s<g} \geq 0$ are the Lagrangian multipliers which are associated with constraints (20) and (21), respectively. Using the Kuhn-Tucker condition, the first-order conditions can be determined:

$$
\begin{aligned}
\left.\frac{\partial L}{\partial v}\right|_{\left(v_{s}^{s,}, c_{s}^{s b}\right)}= & {\left[1+\lambda_{s b 1}^{s<g}-\lambda_{s b 2}^{s<g}\right] \cdot\left[p\left(v_{s}^{s b}, c_{s}^{s b}\right)+v_{s}^{s b} \cdot p_{q}^{\prime}\left(v_{s}^{s b}, c_{s}^{s b}\right)\right.} \\
& \left.-m_{s}\right]+\lambda_{s b 2}^{s<g}\left[m_{d}-m_{s}\right]=0, \\
\left.\frac{\partial L}{\partial c}\right|_{\left(v_{s}^{s,}, c_{s}^{s b}\right)}= & {\left[1+\lambda_{s b 1}^{s<g}-\lambda_{s b 2}^{s<g}\right] \cdot\left[v_{s}^{s b} \cdot p_{y}^{\prime}-k\right]+\lambda_{s b 2}^{s<g} \cdot k=0, } \\
\left.\frac{\partial L}{\partial \lambda_{s b 1}^{s<g}}\right|_{\left(v_{s}^{s b}, c_{s}^{s b}\right)}= & P_{s}\left(v_{s}^{s b}, c_{s}^{s b}\right)-P_{a} \geq 0, \\
\left.\frac{\partial L}{\partial \lambda_{s b 2}^{s<g}}\right|_{\left(v_{s}^{s b}, c_{s}^{s b}\right)}= & -\bar{v}_{s b} \cdot p\left(v_{s}^{s b}, c_{s}^{s b}\right)+J_{d}\left(v_{s}^{s b}, c_{s}^{s b}\right) \geq 0,
\end{aligned}
$$

$$
\begin{aligned}
& \lambda_{s b 2}^{s<g} \geq 0 \\
& \lambda_{s b 1}^{s<g} \geq 0, \\
& \left.\lambda_{s b 2}^{s<g} \cdot \frac{\partial L}{\partial \lambda_{s b 2}^{s c g}}\right|_{\left(v_{s}^{s b}, c_{s}^{s b}\right)}=\lambda_{s b 2}^{s<g} \cdot\left[-v_{s}^{s b} p\left(v_{s}^{s b}, c_{s}^{s b}\right)+J_{d}\left(v_{s}^{s b}, c_{s}^{s b}\right)\right]=0 \text {, }
\end{aligned}
$$

$$
\left.\lambda_{s b 1}^{s<g} \cdot \frac{\partial L}{\partial \lambda_{s b 1}^{s<g}}\right|_{\left(v_{s}^{s b}, c_{s}^{s b}\right)}=\lambda_{s b 1}^{s<g} \cdot\left[P_{s}\left(v_{s}^{s b}, c_{s}^{s b}\right)-P_{a}\right]=0 .
$$

If constrained conditions (20) and (21) are effective and the Lagrangian multipliers $\lambda_{s b 1}^{s<g}>0$ and $\lambda_{s b 2}^{s<g}>0$, then

$$
\begin{gathered}
P_{s}(q, y)-P_{a}=0, \\
P_{s}(v, c)=v p(v, c)-J_{s}(v, c)=J_{d}(v, c)-J_{s}(v, c) .
\end{gathered}
$$

From equations (A.7) and (A.8),

$$
P_{a}=P_{s}^{s b}=J_{d}(v, c)-J_{s}(v, c)=M_{d}-M_{s} .
$$

Note that if profit $M_{d}(v)-M_{s}(v)$ is on the right side of the monopoly optimum (see Figure 2), the private firm will choose travel demand $\bar{v}$ to obtain the monopoly optimum solution. So, the private firm will choose the optimal profit point, i.e., $M_{d}(v)-M_{s}(v)$, on the left side of the monopoly optimum, the corresponding travel demand of which is $v_{d s l}$. Thus, part (a) of Observation 2 is proved.

If constraint (20) is effective and constraint (21) is inactive, the Lagrangian multipliers $\lambda_{s b 1}^{s<g}>0$ and $\lambda_{s b 2}^{s<g}=0$. If $\lambda_{s b 2}^{s<g}=0$, constraint (21) can be ignored. From equations (A.3) and (A.5), we can determine that the private firm will choose $P_{s}(v, c)=P_{a}$ corresponding to travel demand $q_{a l}$ (Figure 2). Thus, part (b) of Observation 2 is proved.

If constraint (21) is effective and constraint (20) is inactive, the Lagrangian multipliers $\lambda_{s b 1}^{s<g}=0$ and $\lambda_{s b 2}^{s<g}>0$. If $\lambda_{s b 1}^{s<g}=0$, we can ignore constraint (20). Then, from equations (A.4) and (A.6), we can determine that the private firm will choose $P_{s}(v, c)=M_{d}-M_{s}$ corresponding to travel demand $v_{d s l}$ (Figure 2). Thus, part (c) of Observation 2 is proved.

If constraints (20) and (21) are inactive, the Lagrangian multipliers $\lambda_{s b 1}^{s<g}=0$ and $\lambda_{s b 2}^{s<g}=0$. We can ignore all of the constraints. The problem becomes a monopoly optimal problem (or the first-best problem of the private firm), and the private firm can obtain the maximum profit $\bar{P}_{s}$. Thus, part (d) of Observation 2 is proved. This completes the proof.

\section{B. Proof of Observation 3}

Proof. It is assumed that $\left(v_{s}^{w w}, c_{s}^{w w}\right)$ is any win-win optimal solution of private problem (26). From constrained optimization problems (26)-(29), the following Lagrange-like function can be defined:

$$
L=W_{s}(v, c)+\lambda_{s w 1}^{s<g}\left[P_{s}(v, c)-P_{a}\right]+\lambda_{s w 2}^{s<g}\left[-v p(v, c)+J_{d}(c)\right],
$$

where $\lambda_{s w 1}^{s<g} \geq 0$ and $\lambda_{s w 2}^{s<g} \geq 0$ are Lagrangian multipliers, which are associated with constraints (27) and (28), respectively. Using the Kuhn-Tucker condition, the first-order conditions can be determined by

$$
\begin{aligned}
& \left.\frac{\partial L}{\partial v}\right|_{\left(v_{s}^{w w}, c_{s}^{w w}\right)}=\left[1+\lambda_{s w 1}^{s<g}-\lambda_{s w 2}^{s<g}\right] \cdot\left[B\left(v_{s}^{w w}\right)-\beta t\left(v_{s}^{w w}, c_{s}^{w w}\right)\right. \\
& \left.-\beta r t^{\prime}(r)-m_{s}\right] \\
& +\lambda_{s w 1}^{s<g} v B_{v}^{\prime}(v)+\lambda_{s w 2}^{s<g}\left[m_{d}-m_{s}-v B_{v}^{\prime}(v)\right]=0, \\
& \left.\frac{\partial L}{\partial c}\right|_{\left(v_{s}^{w w}, c_{s}^{w w}\right)}=\left[1+\lambda_{s w 1}^{s<g}-\lambda_{s w 2}^{s<g}\right] \cdot\left[\beta\left(r_{s}^{w w}\right)^{2} \cdot t^{\prime}\left(r_{s}^{w w}\right)-k\right]=0, \\
& \left.\frac{\partial L}{\partial \lambda_{s w 1}^{s<g}}\right|_{\left(v_{s}^{w w}, c_{s}^{w w}\right)}=P_{s}\left(v_{s}^{w w}, c_{s}^{w w}\right)-P_{a} \geq 0, \\
& \left.\frac{\partial L}{\partial \lambda_{s w 2}^{s<g}}\right|_{\left(v_{s}^{w w}, c_{s}^{w w}\right)}=-v_{s}^{w w} \cdot p\left(v_{s}^{w w}, c_{s}^{w w}\right)+J_{d}\left(v_{s}^{w w}, c_{s}^{w w}\right) \geq 0, \\
& \left.\lambda_{s w 1}^{s<g} \cdot \frac{\partial L}{\partial \lambda_{s w 1}^{s<g}}\right|_{\left(v_{s}^{w w}, c_{s}^{w w}\right)}=\lambda_{s w 1}^{s<g} \cdot\left[P_{s}\left(v_{s}^{w w}, c_{s}^{w w}\right)-P_{a}\right]=0, \\
& \left.\lambda_{s w 2}^{s<g} \cdot \frac{\partial L}{\partial \lambda_{s w 2}^{<<g}}\right|_{\left(v_{s}^{w w}, c_{s}^{w w}\right)}=\lambda_{s w 2}^{s<g} \cdot\left[-v_{s}^{w w} p\left(v_{s}^{w w}, c_{s}^{w w}\right)+J_{d}\left(c_{s}^{w w}\right)\right]=0,
\end{aligned}
$$




$$
\begin{aligned}
& \lambda_{s w 1}^{s<g} \geq 0, \\
& \lambda_{s w 2}^{s<g} \geq 0 .
\end{aligned}
$$

Note that profit $M_{d}(v)-M_{s}(v)$ is on the right side of the monopoly optimum (see Figure 2 ), and the private firm will choose the optimal profit point, $M_{d}(v)-M_{s}(v)$, which is close to the monopoly optimum (Figure 2), the corresponding travel demand of which is $v_{d s r}$. Thus, part (a) of Observation 3 is proved.

If constraint (26) is effective and constraint (27) is inactive, the Lagrangian multipliers $\lambda_{s w 1}^{s<g}>0$ and $\lambda_{s w 2}^{s<g}=0$. If $\lambda_{s w 2}^{s<g}=0$, we can ignore constraint (21). From equations (B.3) and (B.5), we can determine that the private firm will choose $P_{s}(v, c)=P_{a}$ corresponding to travel demand $v_{a r}$ (Figure 2) for the same reason of part (a).Thus, part (b) of Observation 3 is proved.

If constraint (27) is effective and constraint (26) is inactive, the Lagrangian multipliers $\lambda_{s w 1}^{s<g}=0$ and $\lambda_{s w 2}^{s<g}>0$. If $\lambda_{s w 1}^{s<g}=0$, we can ignore constraint (26). Then, from equations (B.4) and (B.6), we can determine that the private firm will choose $P_{s}(v, c)=M_{d}-M_{s}$ corresponding to travel demand $v_{d s} r$ (Figure 2) for the same reason of part (a). Thus, part (c) of Observation 3 is proved. This completes the proof.

\section{Proof of Proposition 2}

Proof. We first take the partial derivatives of social welfare $W_{s}(v, c)$ and private profit $P_{s}(v, c)$ with respect to demand $v$ and capacity $c$. Based on social welfare function $W_{s}(v, c)$ given by (25), we have

$$
\begin{aligned}
& \frac{\partial W_{s}(v, c)}{\partial v}=B(v)-\beta t(v, c)-\beta v \frac{\partial t(v, c)}{\partial v}-m_{s} \\
& \frac{\partial W_{s}(v, c)}{\partial c}=-\left(\beta v \frac{\partial t(v, c)}{\partial c}+k\right)
\end{aligned}
$$

and according to the private profit function given by (18), we have

$$
\frac{\partial P_{s}(v, c)}{\partial v}=R^{\prime}(v)=B(v)-\beta t(v, c)+v B^{\prime}(v)-\beta v \frac{\partial t(v, c)}{\partial v}-m_{s}
$$

$$
\frac{\partial P_{s}(v, c)}{\partial c}=-\left[\beta v \frac{\partial t(v, c)}{\partial c}+k\right]
$$

For exposition simplicity, we define private profit $P_{s}(v)$ and social welfare $W_{s}(v)$ for given $c_{s}^{*}$. Let $\widetilde{v}_{s}$ be the unique $v$ that could maximize $W_{s}(v, c)$; then, with equation (C.1),

$$
B\left(\widetilde{v}_{s}\right)-\beta \cdot t\left(\widetilde{v}_{s}, c_{s}^{*}\right)-\beta \cdot \widetilde{v}_{s} \cdot \frac{\partial t\left(\widetilde{v}_{s}, c_{s}^{*}\right)}{\partial v}-m_{s}=0 .
$$

Let $\bar{q}_{s}$ be unique $q$ that could maximize $P_{s}(q, y)$; then, with equation (C.3)

$$
B\left(\bar{v}_{s}, c_{s}^{*}\right)+\bar{v}_{s} \cdot B^{\prime}\left(\bar{v}_{s}\right)-\beta \cdot t\left(\bar{v}_{s}, c_{s}^{*}\right)-\beta \cdot \bar{v}_{s} \cdot \frac{\partial t\left(\bar{v}_{s}, c_{s}^{*}\right)}{\partial v}-m_{s}=0 .
$$

With Assumption 1, there exist unique $\bar{v}_{s}$ and $\widetilde{v}_{s}$ satisfying (C.5) and (C.6), respectively. By comparing equations (C.5) and (C.6), we can observe that $\bar{v}_{s}<\widetilde{v}_{s}$.

Let $\left(v_{s}^{w w}, c_{s}^{w w}\right)$ be the solution of win-win optimality. Comparing (C.1) and (C.3), we have $\partial W / \partial v>\partial P / \partial v$ for any feasible solution $(v, c)$ with the condition $B^{\prime}(v)<0$. If $\left(v_{s}^{w w}, c_{s}^{w w}\right)$ is a win-win solution, $\partial W\left(v_{s}^{w w}, c_{s}^{w w}\right) / \partial v$ and $\partial P\left(v_{s}^{w w}, c_{s}^{w w}\right) / \partial v$ will not be positive or negative at the same time; otherwise, the change of $v$ will increase or decrease private profit and social welfare simultaneously, which contradicts with the fact that $\left(v_{s}^{w w}, c_{s}^{w w}\right)$ is a win-win optimal solution. Thus, we have $\partial W\left(v_{s}^{w w}, c_{s}^{w w}\right) / \partial v \geq 0$ and $\partial P\left(v_{s}^{w w}, c_{s}^{w w}\right) / \partial v \leq 0$. Then, $\bar{v}_{s} \leq v_{s}^{w w} \leq \widetilde{v}_{s}$.

From Definition 1, we know that $P_{s}\left(v_{s}^{s b}, c_{s}^{*}\right) \leq P_{s}\left(\bar{v}_{s}, c_{s}^{*}\right)$ for given road capacity. If $P_{s}(v, c)$ is the strictly concave function in $v$ and $P_{s}(v, c)$ is the strictly increasing function in $v$ for $v<\bar{v}_{s}$, we have that $v_{s}^{s b}<\bar{v}_{s}$. This completes the proof.

\section{Proof of Proposition 3}

Proof. For constraints (20) and (21), we have $M_{d}-M_{s} \geq P_{a}$, which implies that the objective value of equation (19), $P_{s}$, is in the interval $\left[P_{a}, M_{d}-M_{s}\right]$. Based on Assumption 1, we know that $W_{s}(v, c)$ and $P_{s}(v, c)$ are the concave functions of $v$. According to Proposition 2, we know that $\bar{v}_{s}<\widetilde{v}_{s}$.

Since $W_{s}(v, c)$ is an increasing function of $v$ for $v \leq \widetilde{v}_{s}$ and $P_{s}(v, c)$ is an increasing function of $v$ for $v \leq \bar{v}_{s}, W_{s}(v, c)$ and $P_{s}(v, c)$ are increasing functions of $v$ for $v \leq \bar{v}_{s}$. Then, under the condition of the second-best problem of the private firm, social welfare will increase with private profit. For the profit approaching maximization profit, $M_{d}-M_{s}$, social welfare approaches a maximizing value under the case of the second-best problem of the private firm. So, the larger $M_{d}-M_{s}$ is, the larger the social welfare is.

Since $W_{s}(v, c)$ is an increasing function of $q$ for $v \leq \widetilde{v}_{s}$ and $P_{s}(v, c)$ is a decreasing function of $v$ for $v \geq \bar{v}_{s}, W_{s}(v, c)$ is an increasing function of $v$ for $\bar{v}_{s} \leq v \leq \widetilde{v}_{s}$ and $P_{s}(v, c)$ is an increasing function of $q$ for $v \geq \bar{v}_{s}$. Then, under the condition of the win-win optimal problem, social welfare will decrease with private profit. And with the profit approaching maximization $M_{d}-M_{s}$, social welfare approaches the minimum value under the case of the win-win optimal problem of the private firm. So, the smaller $M_{d}-M_{s}$ is, the larger the social welfare is. This completes the proof.

\section{E. Proof of Proposition 5}

Proof. Assume $c_{d}$ is a given and fixed capacity. Let $\bar{p}_{s}, \widetilde{p}_{s}$, and $\widetilde{p}_{g}^{s<g}$ be the monopoly price of the private firm, social optimal price of the private firm, and social optimal price of the government, respectively. 
According to equation (1), regard $v$ as the function of toll charge $p$ and road capacity $c$. Using the implicit function theorem, we take derivative $v$ with respect to $p$ :

$$
v_{p}^{\prime}=\frac{1}{\left[B_{v}^{\prime}(v)-\beta t_{v}^{\prime}(v, c)\right]} .
$$

For the first-best problem of private firm (18), we take partial derivatives of (19) with respect to $p$, and we have

$$
\frac{\partial P_{s}}{\partial p}=\frac{\partial\left[v p(v, c)-J_{s}(v, c)\right]}{\partial p}=v+p \cdot v_{p}^{\prime}-m_{s} \cdot v_{p}^{\prime}=0 .
$$

Recall equation (E.1). We have

$$
\bar{p}_{s}=m_{s}-v\left[B_{v}^{\prime}(v)-\beta t_{v}^{\prime}\left(v, c_{d}\right)\right] .
$$

For the social optimal problem of private firm (25), we take partial derivatives of (25) with respect to $p$, and we have

$$
\begin{aligned}
\frac{\partial W_{s}}{\partial p}= & \frac{\partial\left[\int_{0}^{v} B(w) d w-\beta v t(v, c)-J_{s}(v, c)\right]}{\partial p} \\
= & B(v) \cdot v_{p}^{\prime}-\left[\beta \cdot t\left(v, c_{d}\right) \cdot v_{p}^{\prime}+\beta v \cdot t_{v}^{\prime}\left(v, c_{d}\right) \cdot v_{p}^{\prime}\right] \\
& -m_{s} \cdot v_{p}^{\prime}=0 .
\end{aligned}
$$

Thus,

$$
\widetilde{p}_{s}=m_{s}+\beta v \cdot t_{v}^{\prime}\left(v, c_{d}\right) .
$$

For the social optimal problem of the government (37), we take partial derivatives of (37) with respect to $p$, and we have

$$
\begin{aligned}
\frac{\partial W_{g}^{s<g}}{\partial p}= & \frac{\partial\left[\int_{0}^{v} B(w) d w-\beta v t(v, c)-J_{g}^{s<g}(v, c)\right]}{\partial p} \\
= & B(v) \cdot v_{p}^{\prime}-\left[\beta \cdot t\left(v, c_{d}\right) \cdot v_{p}^{\prime}+\beta v \cdot t_{v}^{\prime}\left(v, c_{d}\right) \cdot v_{p}^{\prime}\right] \\
& -m_{g}^{s<g} \cdot v_{p}^{\prime}=0 .
\end{aligned}
$$

Thus,

$$
\widetilde{p}_{g}^{s<g}=m_{g}^{s<g}+\beta v \cdot t_{v}^{\prime}\left(v, c_{d}\right) .
$$

From Assumption 1 that $B(v)$ is a decreasing function of $v, B_{v}^{\prime}(v)<0$; recall equations (E.3), (E.5), and (E.7) and $m_{s} \leq m_{g}^{s<g}$; we have $\widetilde{p}_{s} \leq \widetilde{p}_{g}^{s<g}<\bar{p}_{s}$. This completes the proof.

\section{F. Proof of Proposition 7}

Proof. It is assumed that $\left(v_{s}^{s c}, c_{s}^{s c}, n^{*}\right)$ is any optimal solution of problem equations (45)-(48). From constrained optimization problems (45)-(48), the following Lagrange-like function can be defined:

$$
\begin{aligned}
L= & \int_{0}^{v} B(w) \mathrm{d} w-v B(v)+\delta\left[v \cdot p(v, c)-J_{s}(v, c)\right]-(1-\delta) n \\
& +\lambda_{s c 1}^{s<g} \cdot\left[v \cdot p(v, c)-J_{s}(v, c)+n-P_{a}\right]+\lambda_{s c 2}^{s<g} \\
& \cdot\left[-v \cdot p(v, c)+J_{g}(v, c)-n\right],
\end{aligned}
$$

where $\lambda_{s c 1}^{s<g} \geq 0$ and $\lambda_{s c 2}^{s<g} \geq 0$ are Lagrangian multipliers which are associated with constraints (45) and (46), respectively. Using the Kuhn-Tucker condition, the first-order conditions of the problem can be determined by

$$
\begin{aligned}
& \left.\frac{\partial L}{\partial v}\right|_{\left(v_{s}^{s c},,_{s}^{s c}, n^{*}\right)}=-v_{s}^{s c} \cdot B_{v}^{\prime}\left(v_{s}^{s c}\right)+\lambda_{s c 2}^{s<g}\left(m_{g}-m_{s}\right)+ \\
& {\left[\delta+\lambda_{s c 1}^{s<g}-\lambda_{s c 2}^{s<g}\right] \cdot\left[B\left(v_{s}^{s c}\right)-\beta t\left(v_{s}^{s c}, c_{s}^{s c}\right)+v_{s}^{s c} \cdot B_{v}^{\prime}\left(v_{s}^{s c}\right)\right.} \\
& \left.-\beta \cdot v_{s}^{s c} \cdot t_{v}^{\prime}\left(v_{s}^{s c}, c_{s}^{s c}\right)-m_{s}\right]=0, \\
& \left.\frac{\partial L}{\partial c}\right|_{\left(v_{s}^{s c}, s_{s}^{s c}, n^{*}\right)}=\left[\delta+\lambda_{s c 1}^{s<g}-\lambda_{s c 2}^{s<g}\right] \cdot\left[v_{s}^{s c} \cdot p_{c}^{\prime}-k\right]=0, \\
& \left.\frac{\partial L}{\partial \lambda_{s c l}^{s<g}}\right|_{\left(v_{s}^{s c}, c_{s}^{s c}, n^{*}\right)}=P_{s}\left(v_{s}^{s c}, c_{s}^{s c}\right)+n^{*}-P_{a}=v_{s}^{s c} \cdot p\left(v_{s}^{s c}, c_{s}^{s c}\right) \\
& -J_{s}\left(v_{s}^{s c}, c_{s}^{s c}\right)+n^{*}-P_{a} \geq 0, \\
& \left.\frac{\partial L}{\partial \lambda_{s c 2}^{s<g}}\right|_{\left(v_{s}^{s c}, c_{s}^{s c}, n^{*}\right)}=-v_{s}^{s c} \cdot p\left(v_{s}^{s c}, c_{s}^{s c}\right)+J_{g}\left(v_{s}^{s c}, c_{s}^{s c}\right)+n^{*} \geq 0, \\
& \left.\lambda_{s c 1}^{s<g} \cdot \frac{\partial L}{\partial \lambda_{s c 1}^{s<g}}\right|_{\left(v_{s}^{s c}, c_{s}^{s c}, n^{*}\right)}=\lambda_{s c 1}^{s<g} \cdot\left[v_{s}^{s c} \cdot p\left(v_{s}^{s c}, c_{s}^{s c}\right)-J_{s}\left(v_{s}^{s c}, c_{s}^{s c}\right)\right. \\
& \left.+n^{*}-P_{a}\right]=0 \text {, } \\
& \left.\lambda_{s c 2}^{s<g} \cdot \frac{\partial L}{\partial \lambda_{s c 2}^{s<g}}\right|_{\left(v_{s}^{c c}, c_{s}^{s c}, n^{*}\right)}=\lambda_{s c 2}^{s<g} \cdot\left[-v_{s}^{s c} \cdot p\left(v_{s}^{s c}, c_{s}^{s c}\right)+J_{g}\left(v_{s}^{s c}, c_{s}^{s c}\right)\right. \\
& \left.-n^{*}\right]=0 \text {, } \\
& \frac{\partial L}{\partial c}=-(1-\delta)+\lambda_{s c 1}-\lambda_{s c 2}=0, \\
& \lambda_{s c 1} \geq 0 \text {, } \\
& \lambda_{s c 2} \geq 0 .
\end{aligned}
$$

Form equation (F.5) and $0<\delta<1$, we have $\lambda_{s c 1}^{s<g}-\lambda_{s c 2}^{s<g}=$ $1-\delta>0$ and $\lambda_{s c 1}^{s<g}>\lambda_{s c 2}^{s<g}$. With equations (F.6) and (F.7), we know that $\lambda_{s c 1}^{s<g}=0$ and $\lambda_{s c 2}^{s<g}=0$ will not happen simultaneously. From the above analysis, we know that the government must let equation (46) hold, which results in $\lambda_{s c 2}^{s<g}>0$. If the private firm takes part in the bid actively, constraint (45) will be effective, and then $\lambda_{s c 1}>0$. In general, if the government provides guarantee, it will satisfy the 
requirement of the private firm, which also implies the effectiveness of constraint (45).

Then, there is only one case to investigate, namely, $\lambda_{s c 1}^{s<g}>\lambda_{s c 2}^{s<g}>0$. With equations (F.3) and (F.4), we have

$$
\begin{gathered}
v_{s}^{s c} \cdot p\left(v_{s}^{s c}, c_{s}^{s c}\right)-J_{s}\left(v_{s}^{s c}, c_{s}^{s c}\right)+n^{*}-P_{a}=0, \\
-v_{s}^{s c} \cdot p\left(v_{s}^{s c}, c_{s}^{s c}\right)+J_{g}\left(v_{s}^{s c}, c_{s}^{s c}\right)-n^{*}=0 .
\end{gathered}
$$

Recall equations (F.8) and (F.9), and we have

$$
n^{*}=P_{a}-v_{s}^{s c} \cdot p\left(v_{s}^{s c}, c_{s}^{s c}\right)+J_{s}\left(c_{s}^{s c}\right)=J_{g}\left(c_{s}^{s c}\right)-v_{s}^{s c} \cdot p\left(v_{s}^{s c}, c_{s}^{s c}\right) .
$$

This completes the proof.

\section{Data Availability}

The data used to support the findings of this study are available from the corresponding author upon request.

\section{Conflicts of Interest}

The authors declare no conflicts of interest.

\section{Acknowledgments}

This work was supported by the Application-Oriented Undergraduate Pilot Major Construction (Engineering Management Major) Project (Z30011-17-02), the SchoolLevel Project of Shanghai Jianqiao University (SJQ17011), the Central-Level Research Institutes Public Welfare Project (GY2020G-7 and GY2020Z-1), the Science and Technology Committee of Shanghai Municipality (16DZ2290900), and the Ministry of Education Humanities and Social Sciences Fund's Project of the year 2017 (17YJA790007). To Advocate for Legislation for Mandatory Helmets Wearing by E-bike Riders in China (GRSP CHNXX-RD14-1145).

\section{References}

[1] Ministry of Transport of the People's Republic of China, Toll Road Management Regulations (Revised Draft), Ministry of Transport of the People's Republic of China, Beijing, China, 2018, http://www.gov.cn/xinwen/2018-12/21/content_ 5350738.htm.

[2] Z. Tan, H. Yang, and X. Guo, "Properties of Pareto-efficient contracts and regulations for road franchising," Transportation Research Part B: Methodological, vol. 44, no. 4, pp. 415-433, 2010.

[3] B. Niu and J. Zhang, "Price, capacity and concession period decisions of Pareto-efficient BOT contracts with demand uncertainty," Transportation Research Part E: Logistics and Transportation Review, vol. 53, pp. 1-14, 2013.

[4] G. Roth, Roads in a Market Economy, Avebury Technical, Ashgate Publishing Limited, Aldershot, UK, 1996.

[5] E. Engel, R. D. Fischer, and A. Galetovic, "Highway franchising: pitfalls and opportunities," American Economic Review, vol. 87, no. 2, pp. 68-72, 1997.

[6] H. Mohring and M. Harwitz, Highway Benefits: An Analytical Framework, Northwestern University Press, Evanston, IL, USA, 1962.
[7] H. Yang and Q. Meng, "Highway pricing and capacity choice in a road network under a build-operate-transfer scheme," Transportation Research Part A: Policy and Practice, vol. 34, no. 3, pp. 207-222, 2000.

[8] H. Yang and Q. Meng, "A note on "highway pricing and capacity choice in a road network under a build-operate-transfer scheme," Transportation Research Part A: Policy and Practice, vol. 36, no. 7, pp. 659-663, 2002.

[9] Z. Feng, S.-B. Zhang, and Y. Gao, "Modeling the impact of government guarantees on toll charge, road quality and capacity for build-operate-transfer (BOT) road projects," Transportation Research Part A: Policy and Practice, vol. 78, pp. 54-67, 2015.

[10] Z. Feng, Y. Zhang, S. Zhang, and J. Song, "Contracting and renegotiating with a loss-averse private firm in BOT road projects," Transportation Research Part B: Methodological, vol. 112, pp. 40-72, 2018.

[11] F. Wang, M. Xiong, B. Niu, and X. Zhuo, "Impact of government subsidy on BOT contract design: price, demand, and concession period," Transportation Research Part B: Methodological, vol. 110, pp. 137-159, 2018.

[12] S. Shi, Q. An, and K. Chen, "Optimal choice of capacity, toll, and subsidy for build-operate-transfer roads with a paid minimum traffic guarantee," Transportation Research Part A: Policy and Practice, vol. 139, pp. 228-254, 2020.

[13] S. Shi, Y. Yin, and X. Guo, "Optimal choice of capacity, toll and government guarantee for build-operate-transfer roads under asymmetric cost information," Transportation Research Part B: Methodological, vol. 85, pp. 56-69, 2016.

[14] P. Milgrom, "Auctions and bidding: a primer," Journal of Economic Perspectives, vol. 3, no. 3, pp. 3-22, 1989.

[15] E. M. R. A. Engel, R. D. Fischer, and A. Galetovic, "Leastpresent-value-of-revenue auctions and highway franchising," Journal of Political Economy, vol. 109, no. 5, pp. 993-1020, 2001.

[16] G. D. Rus and G. Nombela, "Least present value of net revenue: a new auction-mechanism for highway concessions," University Library of Munich, Munich, Germany, MPRA Paper, 2000.

[17] G. Nombela and G. de Rus, "Flexible-term contracts for road franchising," Transportation Research Part A: Policy and Practice, vol. 38, no. 3, pp. 163-179, 2004.

[18] E. T. Verhoef, "Second-best road pricing through highway franchising," Journal of Urban Economics, vol. 62, no. 2, pp. 337-361, 2007.

[19] B. Ubbels and E. T. Verhoef, "Auctioning concessions for private roads," Transportation Research Part A: Policy and Practice, vol. 42, no. 1, pp. 155-172, 2008.

[20] V. A. C. van den Berg, "Serial private infrastructures," Transportation Research Part B: Methodological, vol. 56, pp. 186-202, 2013.

[21] R. S. Bower, "Impact of regulation on economic behavior: discussion," The Journal of Finance, vol. 36, no. 2, pp. 397-399, 1981.

[22] X. Guo and H. Yang, "Analysis of a build-operate-transfer scheme for road franchising," International Journal of Sustainable Transportation, vol. 3, no. 5-6, pp. 312-338, 2009.

[23] A. M. Spence, "Monopoly, quality, and regulation," The Bell Journal of Economics, vol. 6, no. 2, pp. 417-429, 1975.

[24] N. M. Edelson, "Congestion tolls under monopoly," The American Economic Review, vol. 61, no. 5, pp. 873-882, 1971.

[25] H. R. Varian, Microeconomic Analysis, W. W. Norton \& Company, Inc., New York, NY, USA, 1992. 